
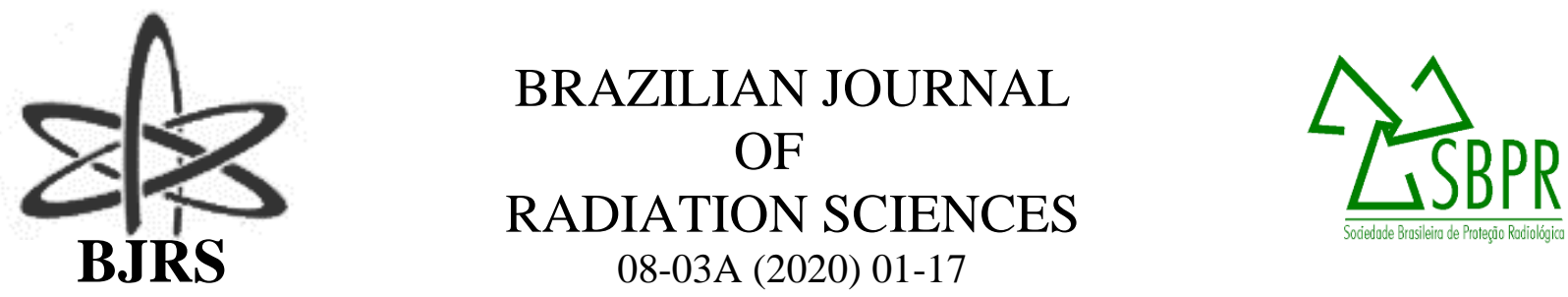

\title{
MODELING LOFW IN A PWR USING MELCOR
}

\author{
Maritza R. Gual, Marcos C. Maturana, Nathália N. Araújo and Marcelo R. Martins
}

\author{
Analysis, Evaluation and Risk Management Laboratory (LabRisco) \\ Polytechnic School of the University of São Paulo \\ Av. Prof. Mello Moraes, 2231 \\ 05508-030, São Paulo, SP, Brasil \\ maritza.gual@labrisco.usp.br
}

\begin{abstract}
The Probabilistic Safety Assessment (PSA) is part of a Nuclear Power Plant (NPP) licensing process. It considers the elaboration and updating of probabilistic models that estimate the risk associated with the operation, allowing the risk monitoring from the design to the plant decommissioning, for both operational as regulatory activities. The PSA identifies those components or plant systems whose unavailability contributes significantly to the Core Damage Frequency (CDF) and to the Large Early Release Frequency (LERF) of radioactive material. Based on the PSA Level 1 results for a reference plant under design, the Analysis, Evaluating and Risk Management Laboratory (LabRisco), located in the University of São Paulo (USP), Brazil, started the analytical investigation of severe accident phenomena using the US Nuclear Regulatory Commission (NRC) MELCOR2.2 code - focusing on the qualification of a group of specialists who will subsidize a PSA Level 2 for the same plant. This PSA Level 1 shows that the accident with large CDF contribution is the Loss of Feed Water Accident (LOFW). Therefore, the initial objective of the investigation was to model the progression of severe accidents during a LOFW for the reference Pressurized Water Reactor (PWR) and to analyze the response of the plant under these accident scenarios. During the course of the hypothetical LOFW in the reference plant, hydrogen was generated - by a reaction between the water and the fuel-clad metal inside the reactor pressure vessel (RPV) but not representing a serious threat to the RPV integrity.
\end{abstract}

Keywords: severe accident, MELCOR, PSA. 


\section{INTRODUCTION}

PSA is a key part of a NPP licensing process [1]. It considers the elaboration and updating of probabilistic models that estimate the risk associated with the operation, allowing the risk monitoring from the plant design to the decommissioning, for both operational as regulatory matters. The PSA of industrial installations is a subject that has evolved with the complexity of the systems [2-3], and presents specific methodologies for some hazard groups - e.g., flood, fire and seismic events [4].

In the nuclear industry, the PSAs are performed for three different levels: from the core damage to a possible radiological release. The PSA Level 1 identifies potential accident sequences and provides an estimate of the frequency they can lead to major fuel failure (i.e., a CDF). After modeling the phenomena that occur due to the sequence of events indicated in PSA Level 1, the PSA Level 2 analyzes the behavior of the containment, evaluates the release of radionuclides, providing frequency estimation and release of radioactive material (i.e., the LERF). The PSA Level 3 analyzes the consequences of a release of radioactive material into the environment and provides an estimate of the effects on public health.

PSAs Level 2 requires a detailed knowledge of severe accident phenomena and analyses of the design vulnerabilities to severe accidents. Given the complexity of these phenomena, some computer codes were developed along the last years to support these analyses. MELCOR, for example, is a fully integrated, engineering-level computer code developed by Sandia National Laboratories (SNL) for the NRC, whose primary purpose is to model the progression of accidents in Light Water Reactor (LWR) NPPs [5-6].

Based on the results of the PSA Level 1 of a reference plant (in the design phase), a study was started with the aim of analyzing the most impacting events to the CDF (i.e., which has the greatest potential to be significant for the LERF in the PSA Level 2. This study is part of a qualification program of a group of specialists from LabRisco, to carry out simulations of a PWR type reactor. In this study, a model in MELCOR was developed for the reference plant. The results for the steady state were compared with the expected for the plant, as presented in [7].This paper discusses the 
initial studies of the LOFW accident, considering the mentioned model (in MELCOR, as presented in a previous paper [7]).

The PSA Level 1 for the reference plant shows that the accident with a CDF contribution is the LOFW. Therefore, the initial objective of the investigation was to model the progression of the severe accident during LOFW for the reference PWR and to analyze the response of the plant under this accident scenario.

Thus, after a brief description of the MELCOR code, this paper presents the reference plant and a summary of the model developed to simulate the evolution of severe accidents in this plant. In the sequence, the results of the PSA Level 1 that motivated the selection of the LOFW (and helped to characterize the contour conditions for the simulated accident) are presented. Finally, the results of the LOFW simulation are presented, including a description of the sequence of events and a discussion of the concentration of hydrogen in the plant containment.

\subsection{SHORT DESCRIPTION OF THE MELCOR COMPUTER CODE}

Several versions of the MELCOR code have been developed by SNL for PSA and source term analysis since 1982. The MELCOR was initially developed as a PSA tool that was to be fast running, making use of necessarily simplified physics models. In recent years, however, MELCOR has found increasing use of the best-estimate tool for severe accident analyses in LWR and many of the physics models have been improved considerably [8-9].

The MELCOR code structure is constructed on separate packages, which model a vast spectrum of severe accident phenomena. The thermal-hydraulic behavior in MELCOR is modeled with governing equations, comprising conservation equations of mass, momentum and energy through control volumes (CV) and flow paths (FL), representing the fluid paths (modeled with FL package) among control volumes (modeled with the CVH package).

There are special packages that are specific to nuclear reactors such as the core heat-up, degradation and relocation (COR), fission product release and radionuclide behavior (RN), fuel dispersal interaction (FDI), corium interaction in the cavity and containment (CAV), among others. 


\subsection{DESCRIPTION OF THE REFERENCE PWR PLANT}

The reference nuclear reactor for this analysis is a PWR which produces $48 \mathrm{MW}$ thermal power. This plant includes two single loops, and comprises the reactor pressure

vessel (RPV), two hot legs feeding U-tube type vertical Steam Generators (SG) respectively, two cold legs - each with three primary reactor coolant pumps -, and a pressurizer (PZR).

The description of the reference PWR plant, the geometric nodalization (CVs), and the heat structures was presented in a previous paper [7]. The main parameters of the plant steady-state are illustrated in Table 1.

Table 1: Main parameters of steady state [7]

\begin{tabular}{cc}
\hline Parameter & Nominal value \\
\hline Core Power, $\mathrm{MWt}$ & 48.00 \\
Primary pressure, $\mathrm{MPa}$ & 13.10 \\
Secondary side pressure, MPa & 3.77 \\
PZR pressure, MPa & 13.10 \\
Coolant Temperature at the core outlet, $\mathrm{K}$ & 558.08 \\
Coolant Temperature at the core inlet, $\mathrm{K}$ & 537.95 \\
Secondary temperature, $\mathrm{K}$ & 519.15 \\
Feed water flowrate, $\mathrm{kg} / \mathrm{s}$ & 9.45 \\
\hline
\end{tabular}

\subsection{MODEL FOR THE REFERENCE PLANT REACTOR COOLING SYSTEM}

The calculations for the main steady-state parameters of this model were compared to the results of a model developed with the code RELAP5 / MOD2 [10]. The general result showed a good agreement between the reference data and the MELCOR calculation (i.e. considering the results of the consulted literature [11-14] ) being used as the basis for this work. 
The input model of the plant is a node representation of the core, RPV, SG, the reactor coolant pumps (RCPs), and the PZR that are enclosed in a steel containment, which is unrounded by a water pool used as shielding and ultimate heat sink, comprising about $72 \mathrm{CVs}$ and 87 FL. Figure 1 shows a simplified diagram of the NPP nodalization.

The hot legs are lumped together with the RPV upper head and the reactor core volumes, and the cold legs with the reactor annular descending channel. The hot leg pipe is simulated by 2 CVs and the cold leg $11 \mathrm{CVs}$. Also, 6 FLs are associated with the 6 reactor coolant pumps.

The Heat Structure package (HS) models the transfers and heat structures in the CVs. The main modeled heat structures were the RPV and their structures, PZR, baffle, SGs tubes and containment.

Relief and safety valves were modeled for each SGs. The PZR contains in addition to the two valves, three banks of electric heaters. The trip of the reactor (SCRAM), the operation of the pumps, valves and heaters were modeled through the package of logical control functions (CF).

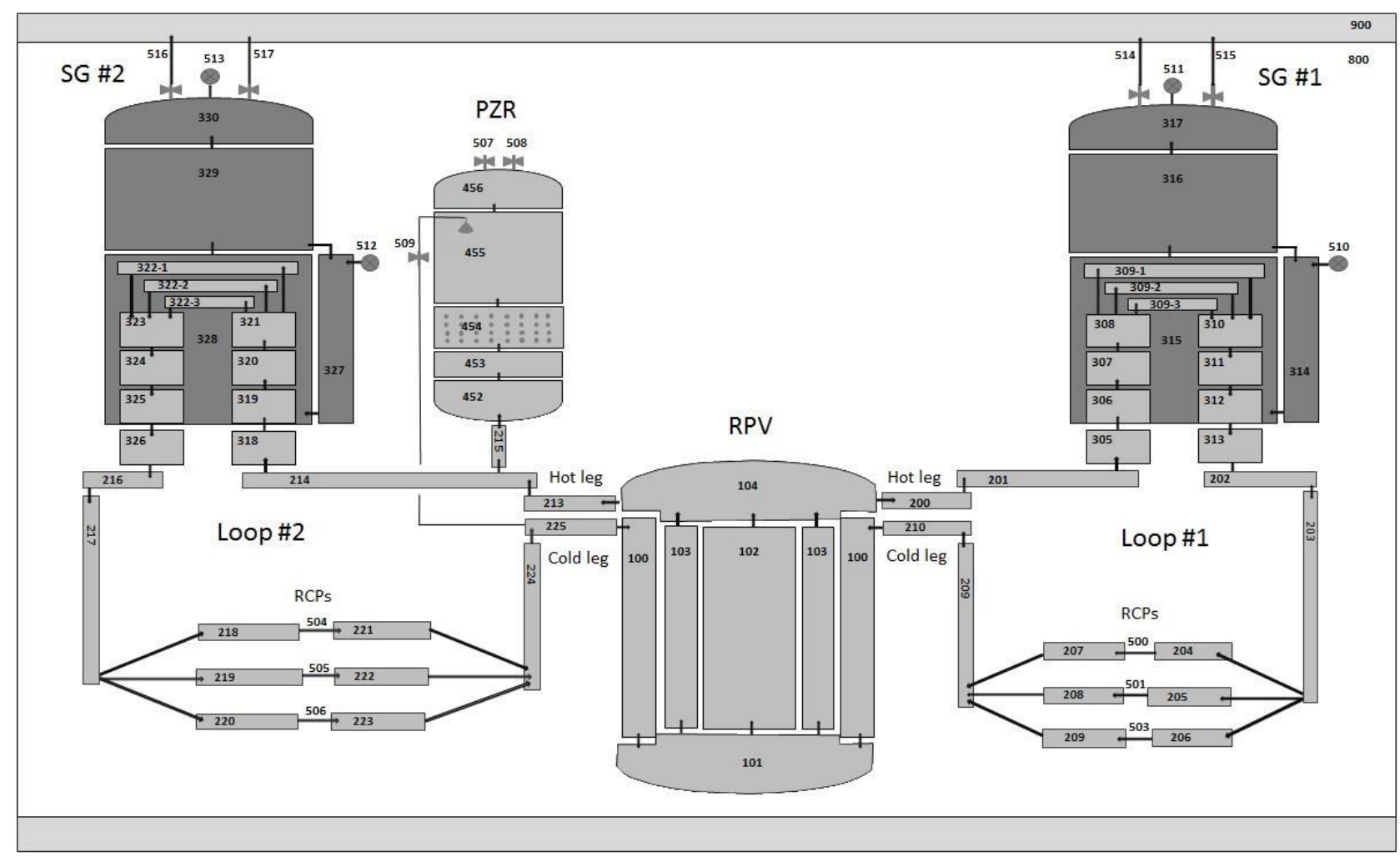

Figure 1: Scheme for the reference NPP model in CVH and FL packages [7] 
The reactor core components, including fuel and control rods, spacer grids and low structures require different input specifications and were modeled in the COR package. The active core was subdivided into 5 axial nodes, while the non-active components, especially the lower grid plate and the supporting structures, were divided into 8 axial nodes. The entire core was subdivided radially into three zones. The mass of UO2 in the reactor core was $3075 \mathrm{~kg}$. The mass of the cladding was $874.40 \mathrm{~kg}$, using MELCOR's default zirconium. The first ring contains 1 fuel assembly, the second ring 6 assemblies, and the third ring 14.

To simulate the accident, a feedwater valve was modeled at the inlet of each SG. After the initial stabilization of the simulation, the valve is closed, initiating the loss of the water.

\subsection{EVENT SELECTION AND DESCRIPTION}

The reference plant PSA level 1 was developed as part of the plant licensing process, i.e., to meet the regulatory requirements of the National Nuclear Energy Commission (CNEN) -which regulates the Brazilian nuclear sector and adopted the NUREG-0800 [15] as a pattern to evaluate the Final Safety Analysis Report (FSAR) of the plant. In its initial version, the PSA Level 1 presented the results in Table 2 [4]. This table shows the groups of initiating events that, in principle, were considered relevant for the calculation of the plant's CDF.

Subsequent evaluations, however, have shown that some of these events contribute little (in relation to the others) to the $\mathrm{CDF}$ - these events can be identified by "*" in the "CDF" column of Table 2. Thus, for example, the frequency of the event "Aircraft Crash" does not result in a relevant contribution to the CDF - this frequency was calculated at $1.25 \mathrm{E}-08 / \mathrm{yr}$ and thus, considering that any aircraft crash results in damage to the reactor core, its contribution to the total CDF would be less than $0.01 \%$. 
Table 2: CDF in the PSA Level 1 [4]

\begin{tabular}{|c|c|c|c|c|}
\hline $\begin{array}{l}\text { Operational } \\
\text { Mode }\end{array}$ & & Initiating Event & $\mathrm{CDF}(/ \mathrm{yr})$ & $\begin{array}{l}\text { Percentage of } \\
\text { Total CDF }\end{array}$ \\
\hline \multirow[t]{10}{*}{ Full Power } & Internal & Transients & 3.99E-06 & $1.80 \%$ \\
\hline & Events & Loss of Coolant Accident (LOCA) & $3.30 \mathrm{E}-06$ & $1.49 \%$ \\
\hline & & $\begin{array}{c}\text { Anticipated Transient Without } \\
\text { SCRAM (ATWS) }\end{array}$ & $3.26 \mathrm{E}-07$ & $0.15 \%$ \\
\hline & & $\begin{array}{l}\text { Interfacing Systems Loss of Cool- } \\
\text { ant Accident (ISLOCA) }\end{array}$ & $*$ & $0.00 \%$ \\
\hline & External & Seismic Events & $*$ & $0.00 \%$ \\
\hline & Events & Internal Fire & $1.66 \mathrm{E}-04$ & $74.75 \%$ \\
\hline & & Internal Flood & $3.25 \mathrm{E}-06$ & $1.46 \%$ \\
\hline & & Tornado & $*$ & $0.00 \%$ \\
\hline & & External Flood & $*$ & $0.00 \%$ \\
\hline & & Aircraft Crash & $*$ & $0.00 \%$ \\
\hline \multirow[t]{2}{*}{$\begin{array}{c}\text { Low Power } \\
\text { and } \\
\text { Shutdown }\end{array}$} & $\begin{array}{l}\text { Internal } \\
\text { Events }\end{array}$ & Shutdown & $4.52 \mathrm{E}-05$ & $20.35 \%$ \\
\hline & & Total CDF & 2.22E-04 & $100 \%$ \\
\hline
\end{tabular}

In a PSA, the cut sets represent the failure events necessary to achieve an accident sequence state - i.e., these are the individual events making up a cut set and which, occurring together, may cause core damage. In the Internal Events PSA Level 1 (for transients) for the reference plant, the LOFW initiating event appears in the cut set with the highest frequency (the highest contribution to the CDF of the plant, therefore). The events considered in this cut set were presented in Table 3.

Table 3: Cut set with the highest frequency in the PSA Level 1

\begin{tabular}{lcc}
\hline Event Description & $\begin{array}{l}\text { Event } \\
\text { Probability }\end{array}$ & $\begin{array}{l}\text { Cut Set Frequency } \\
(/ \mathbf{y r})\end{array}$ \\
\hline Loss of Main Feed Water & $1.77 \mathrm{E}-1$ & \\
& $1.00 \mathrm{E}+0$ & $3.10 \mathrm{E}-6$ \\
$\begin{array}{l}\text { Plant is at power operation based on annual } \\
\text { availability }\end{array}$ & $1.00 \mathrm{E}+0$ & \\
SCRAM Successful & $1.80 \mathrm{E}-5$ & \\
$\begin{array}{l}\text { Comm. cause failure of the Safety Control } \\
\text { System (SCS) Controller } \\
\text { Transient with loss of residual heat cooling (by }\end{array}$ & $1.00 \mathrm{E}+0$ & \\
\hline
\end{tabular}


primary side and secondary side systems)

The LOFW accident could happen due to either Main Feed Water (MFW) pump trip or malfunction of MFW valves provided no water is supplied to SGs. It is assumed that, the LOFW occurred coincident with the failure of the Safety Control System (SCS) controllers to operate. And with one SG2 (in the secondary loop) functional is postulated, as presented in Table 4.

Table 4: Postulated LOFW Scenario

\begin{tabular}{lll}
\hline Scenario & Description & SCRAM \\
\hline SG \#2 & LOFW + emergency cooling system failure & YES \\
\hline
\end{tabular}

Thus, considering the cut set presented in Table 3 and the description of the initiating event, the LOFW for the simulation presented in this paper assumes the following events: 1) The reactor is operating at the initial nominal power $100 \%$; 2) The SG level starts to decrease rapidly because of the water evaporation and the steam flow to the turbine; 3) The SCRAM system is available and operational; 4) The SCS fails to start; 5) An auxiliary Feed Water (AFW) and Emergency Feed Water (EFW) system fail to start.

For the definition of the plant conditions at the time of occurrence of the LOFW initiating event, as considered in the PSA Level 1, the data presented in Table 5 are assumed, based on the expected values for the steady-state of the plant [7]. Besides that, the SCRAM conditions are supposed to be the sensors independent from the existing reactor protection system. And, for the pressurizer safety valves, the safety valve is considered. 
Table 5: Boundary Conditions [7]

\begin{tabular}{ccc}
\hline \multicolumn{2}{c}{ Reactor SCRAM signal } & Condition actuation \\
\hline & Low level of PZR & $1.13 \mathrm{~m}$ \\
& High level of PZR & $2.37 \mathrm{~m}$ \\
Reactor SCRAM signal & Low level an any GV & $2.13 \mathrm{~m}$ \\
& High level an any GV & $2.68 \mathrm{~m}$ \\
& Containment pressure & $>0.13 \mathrm{MPa}$ \\
& Opening set point- \#1 & $15.15 \mathrm{MPa}$ \\
& Closing set point- \#1 & $13.40 \mathrm{MPa}$ \\
PZR safety valve & Opening set point- \#2 & $15.96 \mathrm{MPa}$ \\
& Closing set point- \#2 & $14.36 \mathrm{MPa}$ \\
PZR spray system & Opening set point & $13.45 \mathrm{MPa}$ \\
(determined by an over-pressure & Closing set point & $13.17 \mathrm{MPa}$ \\
signal) & Primary circuit pressure & \\
& (PI) & $<13.1 \mathrm{MPa}$ \\
Other boundary conditions & Primary cooling rate & $<115.0 \mathrm{~kg} / \mathrm{s}$ \\
\hline
\end{tabular}

\section{SEQUENCE OF EVENTS}

In the current investigation, it is tried to simulate the response of the reference PWR nuclear reactor to the LOFW accident in order to calculate the hydrogen volumetric concentration in containment and comparing with the safety limit reported in NRC regulation 10 CFR 50.44 [16] and IAEA report [17].

NRC regulation, 10 CFR 50.44 [16] limits hydrogen concentration to less than 10 percent, the likelihood of deflagration-to-detonation transition is assumed to be zero if the hydrogen concentration is less than 10 percent. According to IAEA report [17], if the volumetric concentration of hydrogen in different compartments of the containment remains below about 10\%, as would be generated from a $100 \%$ fuel clad metal-water reaction, hydrogen combustion, is not expected - e.g., calculation suggested that in case of deflagration $200 \mathrm{~kg}$ of hydrogen is involved and $80 \mathrm{~kg}$ of hydrogen is involved in detonation in Fukushima-Daiichi accident [18]. Table 6 represents the sequence of events for the LOFW accident analyzed with MELCOR version 2.2 - obtained considering the results presented in the next section. The reactor scram occurs with a delay of $7 \mathrm{sec}$. 
Table 6: Sequence of events

\begin{tabular}{ll}
\hline Time $(\mathrm{s})$ & Event Description \\
\hline 0.0 & Steady state \\
206.00 & The loss of the SG feed water occurs. SG level drop rapidly \\
Reactor trip (SCRAM occurs successful) caused by SG water level below \\
the nominal level (Figure 2). \\
RCPs tripped of primary circuit caused by trip of feed water valve of SG. \\
208.30 & PZR spray valve is open (PI> 13.45 MPa) \\
209.35 & PZR first safety valve opening (PI >15.15 MPa) \\
211.42 & PZR second safety valve is fully opened (PI >15.96 MPa) \\
220.05 & Loss of the core decay power (Figure 3). Water level of the core (Figure 3) \\
& and coolant mass flow rate (Figure 4) begins to decrease (<115.0 kg/s). \\
& Increase of inlet and outlet temperature (Figure 5) \\
& Increase of primary and secondary pressure (Figure 6) \\
234.50 & Maximum void fraction in the upper head (=0.4). Starts of core uncover \\
237.07 & (Figure 7) \\
& Decrease of primary pressure (Figure 6) \\
255.55 & Start the hydrogen production by oxidation (Figure 11) \\
260.00 & Amount of hydrogen in core (0.0003 Kg) (Figure 11) \\
260.11 & One of 2 safety valves of SG is fully open (PI < 13.1 MPa) \\
242.26 & Peak fuel cladding temperature (Figure 10) \\
300.10 & Maximum hydrogen production (0.0987 Kg) (Figure 11) \\
302.61 & Maximum amount of hydrogen in core (0.003 Kg) (Figure 11) \\
500.21 & Maximum amount of hydrogen in containment (0.06 Kg) (Figure 11) \\
760.00 & Maximum pressure shielding pool (Figure 8) \\
920.14 & Maximum pressure in shielding pool (Figure 8) \\
3120.07 & Fist peak temperature in RPV (Figure 9a) \\
$120,000.00$ & Maximum temperature in containment (Figure 9b) \\
& Maximum temperature in RPV (Figure 9) \\
& End of calculation \\
&
\end{tabular}

\section{RESULTS OF CALCULATIONS}

In this study, the loss of feed water in SG\#2 is analyzed. The results of accident analyses are shown in figures 2-14. The AptPlot software [19] was used to plot the parameter values in curves. 


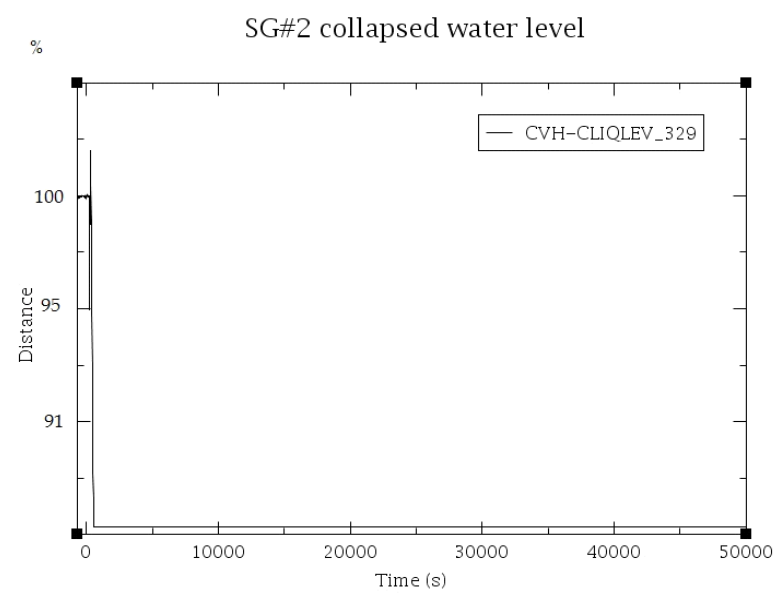

Figure 2: SG\#2 collapsed water level.

Coolant mass flow rate

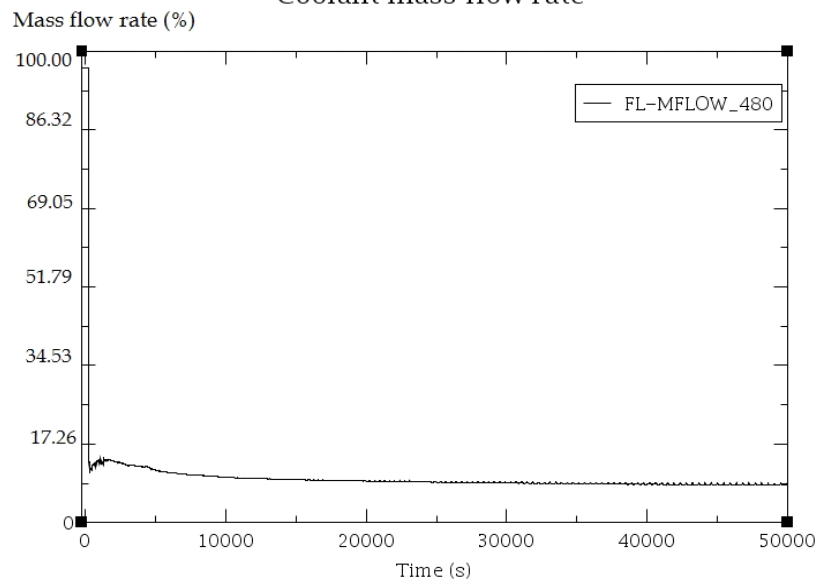

Figure 4: Core mass flow rate.

Primary and secondary pressure

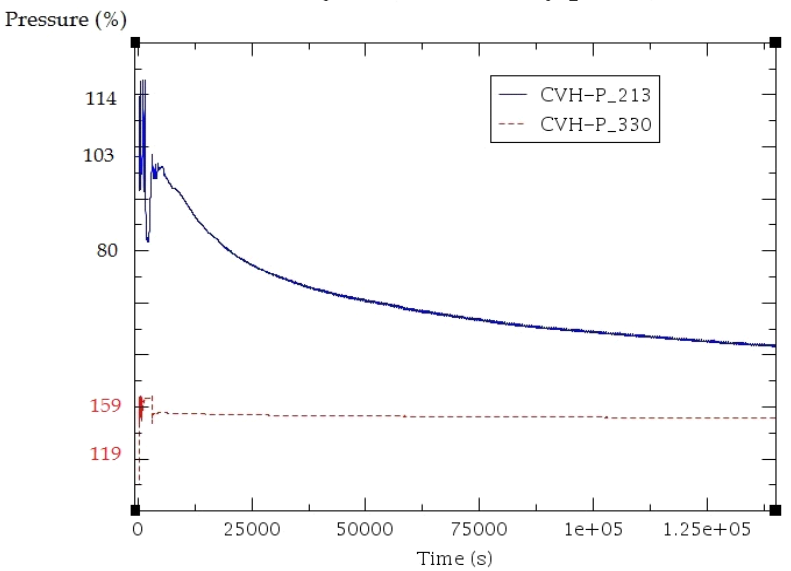

Figure 6: Primary and secondary pressure.

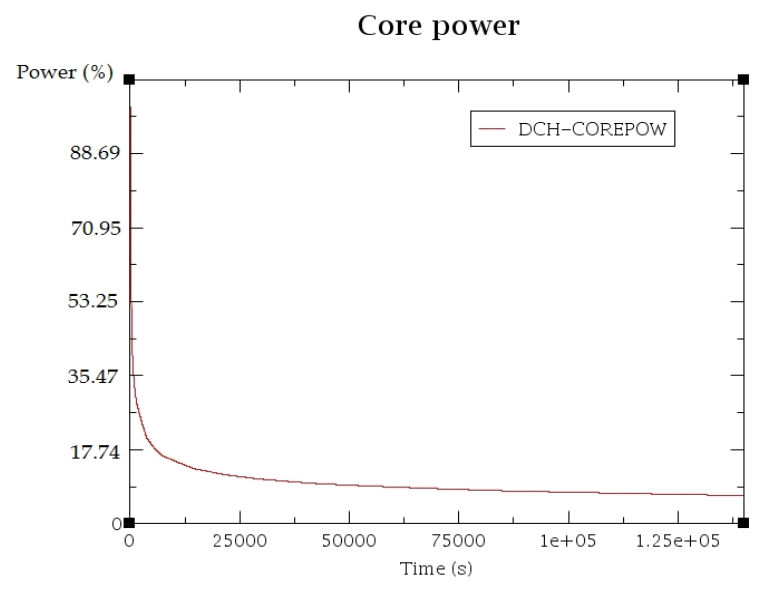

Figure 3: Core decay power.

Inlet and outlet cooling temperature

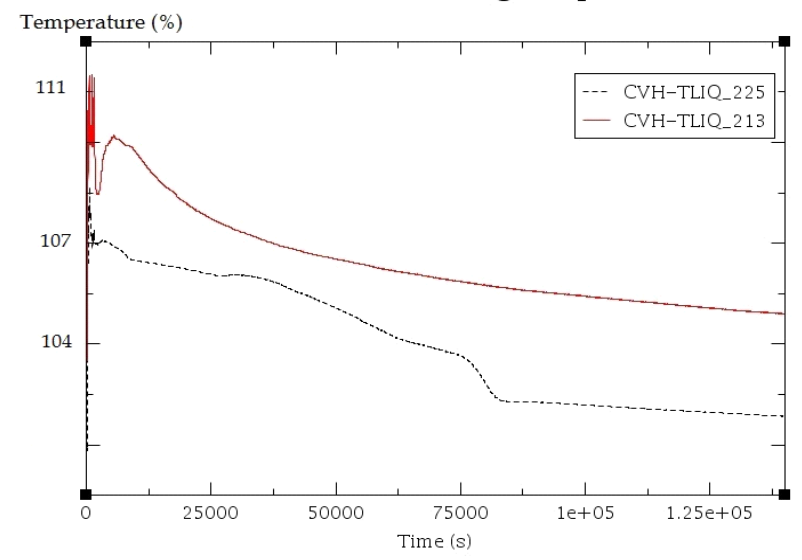

Figure 5: Coolant Temperature at the core inlet and outlet.

Void fraction in upper head and core

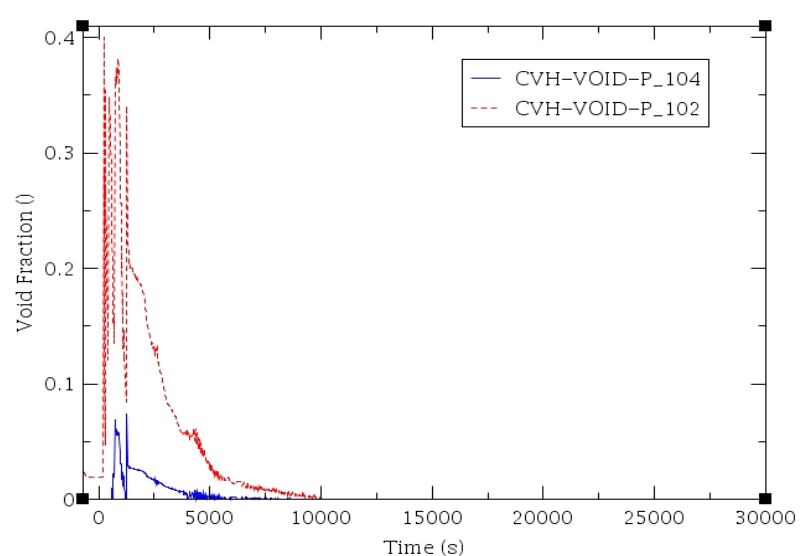

Figure 7: Void fraction in upper head and core 


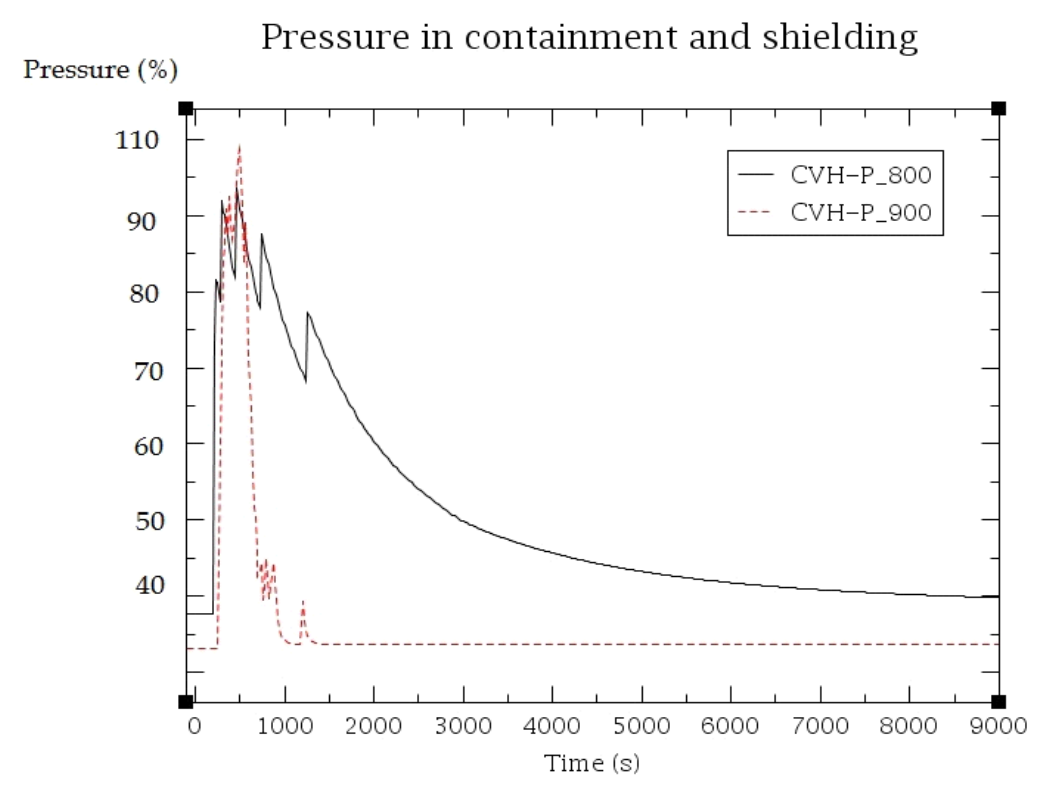

Figure 8: Containment and shielding pool pressure.
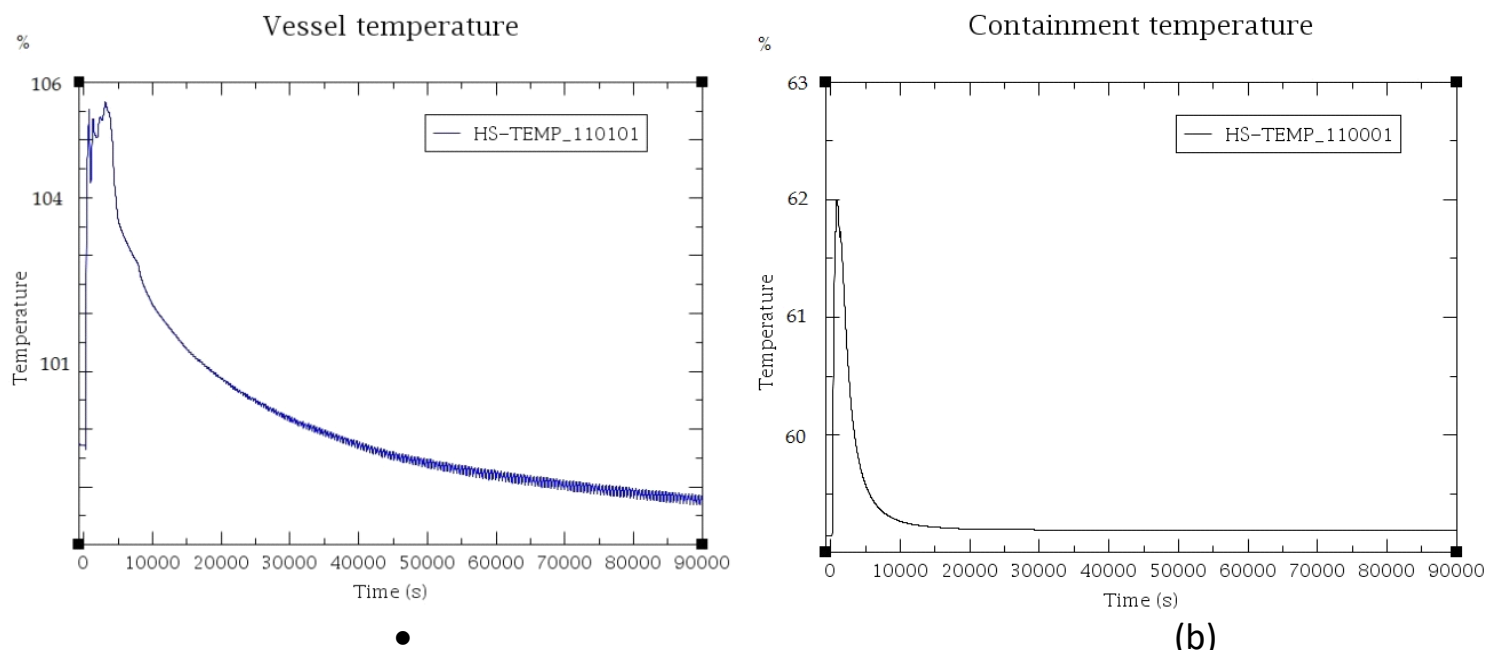

Figure 9: a) Temperature in RPV and b) Temperature in containment. 


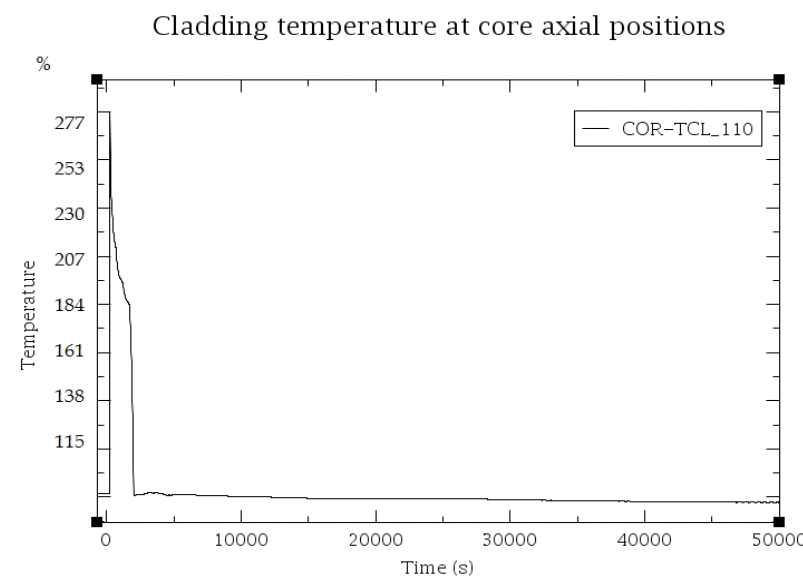

Figure 10: Cladding temperature at core axial positions.
Hydrogen production by oxidation

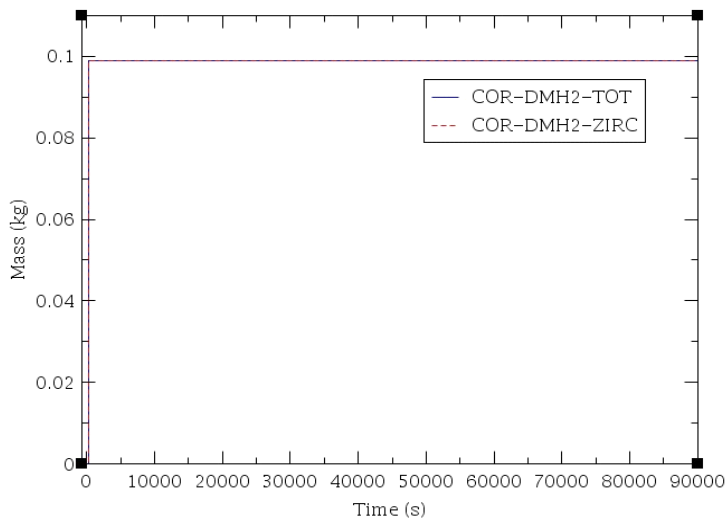

Figure 11: Calculated total cumulative hydrogen production by oxidation of material in core.

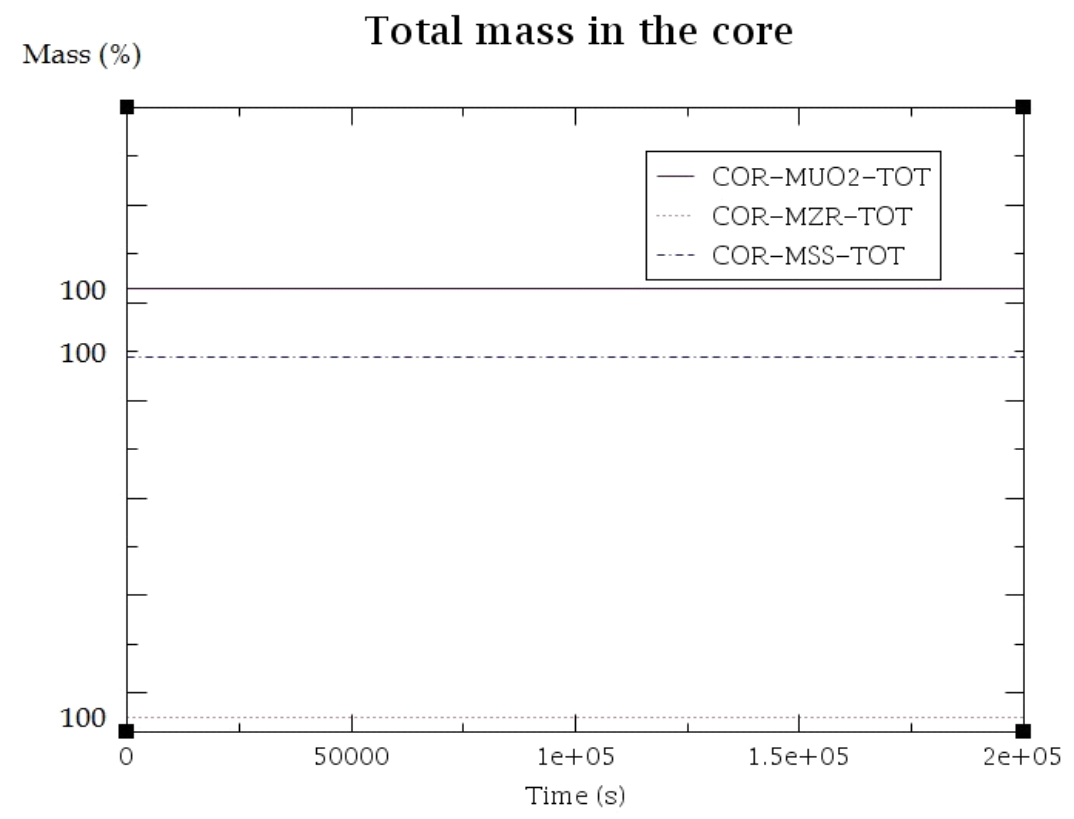

Figure 12: Total mass in the core. 
Total debris mass ejected through vessel breach

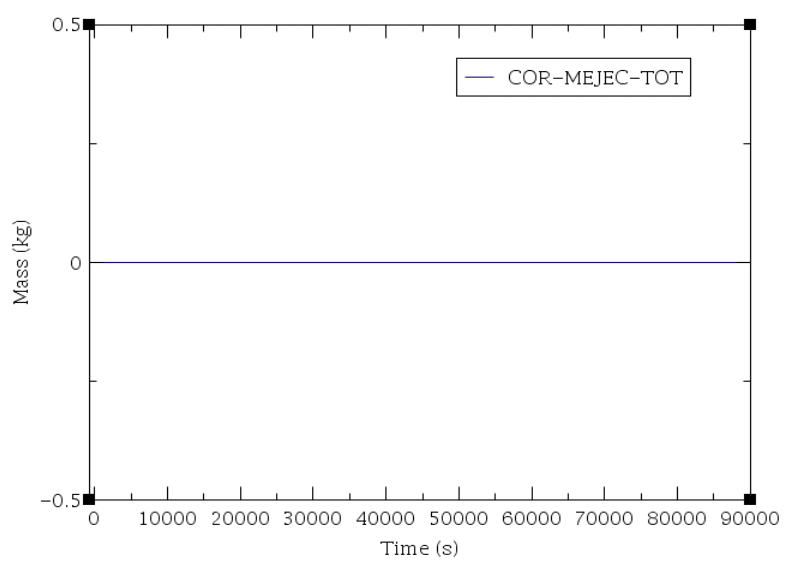

Figure 13: Total debris mass ejected through vessel breach.
Hydrogen mass

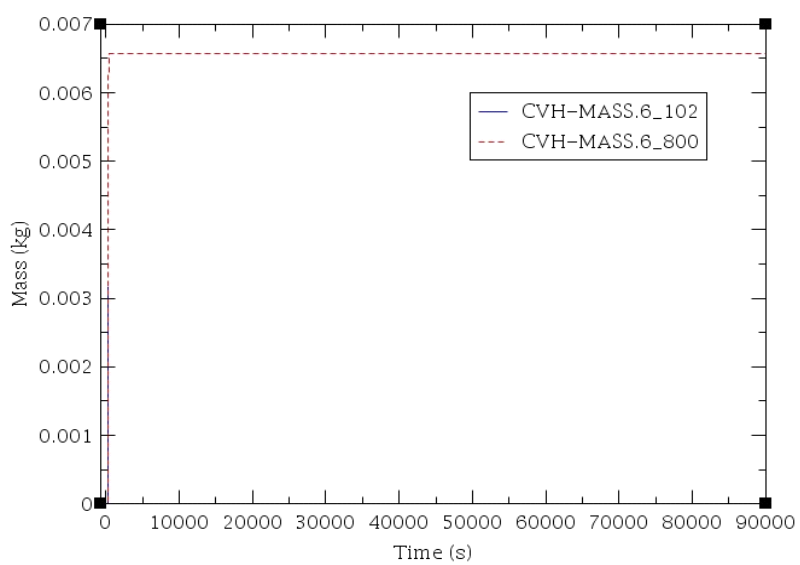

Figure 14: Hydrogen generation in core and containment.

The following remarks were obtained from these simulation results:

a) The core level begins to drop because the steam flow rate into the SG \#2 is decreasing caused by the feedwater pumps tripped.

b) There is a SCRAM when all the control rods are inserted and the reactor is shut down, the fission reactions essentially stop and the decay power drops (Figure 3), but not drops to zero by fission products accumulation.

c) Figure 6 shows the primary and secondary pressure behavior during the accident progression. The pressure into the containment in this accident is caused by high pressure in the primary and secondary pressure, as shown in Figure 6.

d) When feedwater level in SG \#2 begins decreasing (Figure 2), the core begins to uncover by the coolant (Figure 4). The upper head and core never are empty, as shown in Figure 7.

e) As the core water level is decreasing, the temperature of cladding is increasing. The maximum cladding temperature is less than melt temperature ( $T=2098 \mathrm{~K})$ for zircaloy [6] (Figure 10). 
f) Hydrogen mass is generated by in-vessel from the oxidation reactions of zirconium, as shown in Figure 11.

g) The maximum temperature in RPV is less than melt temperature $(\mathrm{T}=1810 \mathrm{~K})$ for carbon steel [6] (Figure 9).

h) The masses of all components in the system, does not change in time (Figure 12), because the RPV not collapsed. The core is not relocated to the bottom of the lower head because the reactor vessel not fails (Figure 13).

i) The results in Figure 14 show that the concentration of hydrogen generated in the core $(3 \mathrm{~g})$ and the containment (60 g), is low to produce deflagration and detonation [18]; therefore, the integrity of the containment is not damaged.

\section{CONCLUSION}

In the current investigation, the response of the reference PWR nuclear reactor to the LOFW accident (with one SG functional) was simulated in order to calculate the hydrogen volumetric concentration in containment and comparing with the safety limit reported in NRC regulation and IAEA. It was verified that the hydrogen concentration during and following such an accident is low; therefore, the reference plant remains in a safe condition.

Thus, the main results of the study gave out the integrity of reference PWR NPP when the LOFW accident occurred. Besides, this was demonstrated that the hydrogen production is less than $1 \mathrm{~kg}$.

Posteriorly, these results will be used to study the action of safety important and equipment systems to avoid the dry out of the reactor core and the fuel cladding temperature rising. 


\section{REFERENCES}

[1] U.S. Nuclear Regulatory Commission -USNRC. Probabilistic Risk Assessment and Severe accident Evaluation for New Reactors, NUREG-0800, Section 19.0, Washington, D. C., (2007).

[2] M. R. Hayns. The Evolution of Probabilistic Risk Assessment in the Nuclear Industry, Institution of Chemical Engineers, Trans I, v. 77, Part B, (1999).

[3] M. R. Martins, P. F. F. Melo and M. C. Maturana. Methodology for system reliability analysis during the conceptual phase of complex system design considering human factors. In: Proceeding of the ANS PSA 2015 International Topical Meeting on Probabilistic Safety Assessment and Analysis, Sun Valley, ID, April 26-30, 2015, on CD-ROM, American Nuclear Society, LaGrange Park, IL, (2015).

[4] M. C. Maturana, L. L. Bruno, and M. R. Martins, Application of Fire PSA in Defining System Reliability Criteria: Detection and Suppression Systems in I\&C Electrical Panel Room, In: Proceedings of Probabilistic Safety Assessment and Management - PSAM 14, Los Angeles, CA, September, (2018).

[5] L.L. Humphries, et al. MELCOR Computer Code Manuals Vol. 1: Primer and Users' Guide Version 2.2.9541 (2017).

[6] L.L. Humphries, et al. MELCOR Computer Code Manuals Vol. 2: Primer and Users' Guide Version 2.2.9541 (2017).

[7] N. N. Araújo, M. C. Maturana, M. R. Gual, Analytical Simulation of a PWR Using MELCOR Code, In: INTERNATIONAL NUCLEAR ATLANTIC CONFERENCE- INAC 2019, Santos, SP, Brazil, October 21-25 (2019).

[8] J. Cardoni, R. Gauntt, D. Kalinich and J. Phillips, MELCOR simulations of severe accident at Fukushima Daiichi Unit 3, Nuclear Technology, 2, Volume 186 (2014).

[9] T. Sevon, A MELCOR model of Fukushima Daiichi Unit 3 accident, Nuclear Engineering and Design, 284, pp. 80-90, April (2015). 
[10] M. Genta Maragni, A. Belchior Junior and J. A. Onoda Pessanha. Modelagem de estado estacionário do reator da INAP com o RELAP5/MOD2, In: INTERNATIONAL NUCLEAR ATLANTIC CONFERENCE- INAC 1997 (1997).

[11] M. Malcki, L. Pienkowski, K. Skolik, Simulation of SB-LOCA of typical PWR with MELCOR code, In: IOP Conference Series Earth and Environmental Science,214:012071, January (2019).

[12] M Pescarini, F. Mascari, D. Mostacci and F De Rosa, Analysis of unmitigated large break loss of coolant accidents using MELCOR code, Journal of Physics Conference Series 923, Volume 1,012009, November (2017).

[13] Y. Jin, W. Xu, X. Liu, In- and ex-vessel coupled analysis of IVR-ERVC phenomenon for large scale PWR, Annals of Nuclear Energy, Volume 80, pp. 322-337, June (2015).

[14] M. Pavlova, P. P Groudev and V. Hadjiev, Development and validation of VVER-1000 input deck for severe accident calculations with MELCOR Computer Code, In: XV International School on Nuclear Physics, Neutron Physics and Nuclear Energy, Varna, Bulgaria, October (2003).

[15] NUREG-0800: Standard Review Plan for the Review of Safety Reposts for NuclearPower Plants: LWR Edition, Revision 2, June (2007).

[16] USNRC Regulations Title 10, Code of Federal Regulations (CRF), Part 50 - Domestic Licensing of Production and Utilization Facilities, Section 50.44 Combustible gas control for nuclear power reactors, January 1( 2011).

[17] Y. Abou-Rjeily, G. Cénérino, A. Drozd, S. Lee, J. Misak, C.O. Park, et al. International Atomic Energy Agency, Mitigation of Hydrogen Hazards in Severe Accident in Nuclear Power Plants, IAEA-TECDOC-1661 (2011).

[18] J. Yanez J, M. Kuznetso, A. Souto-Iglesias A. An analysis of the hydrogen explosion in the Fukushima Daiichi accident, Int J Hydrogen Energy, Volume 40, pp. 8261-8280 (2015).

[19] AptPlot 6.8.0 / ACS Plug-in 2.3.0 - released December 1 (2017). 